RESEARCH PAPER RP919

Part of Journal of Research of the National Bureau of Standards, Volume 17, September 1936

\title{
THERMAL CONTROL IN MINIMUM-DEVIATION REFRAC. TOMETRY AND TEMPERATURE COEFFICIENTS FOR A MEDIUM FLINT GLASS
}

\author{
By Leroy W. Tilton
}

\section{ABSTRACT}

Constructional details are given for a constant-temperature housing for minimum-deviation measurements on a spectrometer, and the operational procedure is described. Provision is made for mounting and properly adjusting the prism in a temperature-controlled bath of stirred air contained in a waterjacketed cylinder provided with plane-parallel windows that are adjustable for use over a wide range of prism angles and refractive media. Typical temperature coefficients of refractivity are given for a medium flint glass.

\section{CONTENTS}

I. Introduction

II. Constant-temperature prism housing

1. General description

2. Constructional details

3. Jacketing circuit

4. Suspension and counterbalance

III. Operational procedure

1. Refracting-angle measurements (by autocollimation)

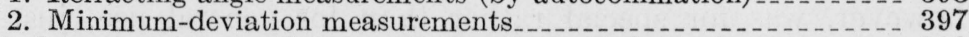

IV. Typical temperature coefficients of refraction and dispersion

\section{INTRODUCTION}

Certain requirements of sixth-decimal place refractometry have been discussed by the writer in former papers, ${ }^{1}$ and some indications have been given concerning procedures that should be followed in using a spectrometer and the minimum-deviation method for precise and accurate determinations of refractive index. Of the procedures outlined, the most difficult from the experimental standpoint is the design, construction, and use of an adequate prism housing ${ }^{2}$ for control of both air and prism temperatures while minimum deviations are observed.

Aside from the obvious advantages of such a housing for an accurate determination of refractivity at any given temperature, its use is desirable in determining precise values for temperature coefficients of index, not only at ordinary room temperatures but at others somewhat different therefrom. This is particularly so since interferometric methods ${ }^{3}$ of determining such thermo-optical properties

${ }^{1}$ BS J. Research 2, 909-930 (1929) RP64; 6, 59-76 (1931) RP262; 11, 25-57 (1933) RP575; J. Research NBS

14, $393-418$ (1935) RP776.
See brief discussion on p. 919 and 920 of first citation in footnote 1 . These difficulties influenced J. F. Eckman when he rejected minimum deviation and designed his constant-deviation refractometer. See p. 14 of Rec. trav. chim. 13 (1894).

3 See, for example, C. G. Peters, BS Sci. Pap. 20, 635-659 (1926) S521. 
are usually unreliable at and near room temperatures, on account of what is sometimes called the "starting effect". "Also, a temperature-control housing is desirable because only a limited temperature range is available in using a constant-temperature room.

In the literature, however, a certain scepticism is sometimes expressed regarding the advisability of depending upon a housing, rather than upon a constant-temperature room, when determining temperature coefficients of index. This paper is consequently written not only to describe a successful housing suitable for general spectrometric use, but also to give in detail results which indicate that its use is satisfactory.

\section{CONSTANT-TEMPERATURE PRISM HOUSING}

The prism housing used by J. Macé de Lépinay ${ }^{5}$ is probably sufficiently characteristic of the best previous efforts to provide minimum-deviation housings for work on prisms of solid media. His prism was immersed in air that in turn was surrounded on sides and top by an insulated and water-jacketed box or cover. Fixed lateral openings for the entrant and emergent light were closed with thick wooden stoppers except during the actual measurements.

More elaborate housings have been used by W. H. Perkin, ${ }^{6}$ also by E. E. Hall and A. R. Payne, ${ }^{7}$ for work on liquids contained in a hollow prism, but even in these the housing windows were opaque and therefore were opened during measurements. G. P. Baxter, L. L. Burgess, and $\mathrm{H}$. W. Daut ${ }^{8}$ avoided this undesirable procedure by having the telescope and collimator tubes extend into the air bath and by providing adjustable shutters which made a tight fit with these tubes. Moreover, they devised a separate mounting to avoid placing the extra weight on the spectrometer. Even this design, however, was for special rather than for general use, just as had been the case with all previous housings for minimum-deviation measurements.

\section{GENERAL DESCRIPTION}

The prism housing that has been used for several years in this laboratory was designed by F. A. Case of the Optical Instruments Section and built in the Bureau's Instrument Shop. It consists (see figs. 1 to 4 , inclusive), primarily of two vertical concentric hollow cylinders of brass each containing a circular window of glass. The inner cylinder and its integrally connected top are double walled to form a water jacket. The outer cylinder or single-walled sleeve fits closely and rotates around the double walls of the inner cylinder. This whole superstructure rotates on and is readily removable from low vertical walls at the periphery of a water-jacketed base which is firmly attached to the prism table of the spectrometer.

Lateral openings are, of course, necessary in the walls of the inner cylinder and also in the sleeve in order to permit the simultaneous

${ }^{4}$ See C. Cuthbertson, Trans. Roy. Soc. (London) [A] 204, 331 (1905). This starting effect consists of irregular fringe shifts which occur before the temperature gradients within the interferometer have assumed the values which correspond to a steady heating rate. Even if both heating and cooling are successively employed in a continuous and regular series of observations, including temperatures both higher and lower than those of the room, some degree of undesirable fringe shift must occur at and near room temperatures because of reversals which must take place in the temperature gradients.

$\checkmark$ Ann. chim. phys. [7] 5, 216-232 (1895).

6 J. Chem. Soc. 61, 287-290 (1892).

7 Phys. Rev. [2] 20, 249-258 (1922).

8 J. Ám. Chem. Soc. 33, 893-901 (1911). 
use of both windows, one for the entrant and one for the emergent light. These lateral openings are sufficiently wide to permit a clear aperture of at least $2 \mathrm{~cm}$ in width over a range of deviations from 17 to 81 degrees of arc. Clamps and slow-motion screws are provided for adequate orientation adjustments; first, of the inner cylinder and window with respect to the prism and, second, of the rotating sleeve and its window with respect to the inner cylinder and the first window. These clamps are designed to operate at all positions around the circumference of the housing. The whole metal exterior of the prism housing is covered with felt and asbestos.

Secured to the upper floor of the water-jacketed base are two prism slides that travel in superimposed ways at right angles with each other. These slides are actuated by slow-motion screws that are controlled from without the prism housing. Two circular wells in the double-walled top permit the insertion of thermometers to desired depths in the air bath. Through a third opening in the center of the top an air stirrer is inserted. This consists of a small vertical shaft carrying two sets of propeller blades. The upper set, outside the housing, is driven by a compressed-air jet; the lower stirs the air bath within the housing. This device gives adequate stirring with a minimum of weight, volume, and vibration as compared with a stirrer operated by other means.

The window cells are hinged at their tops on horizontal axes and are fastened at the base by adjusting screws. These screws turn the windows through a vertical angle of a few degrees and thus permit autocollimated reflections from the windows to be properly returned to, or entirely excluded from, the field of view of the telescope. The window frames are fitted with rubber sills to give effective closing for a range of adjusted orientations about the horizontal hinges of the cells.

The windows are of borosilicate crown glass of good quality. Their surfaces are flat within $1 / 4 \lambda$ over their clear $49-\mathrm{mm}$ aperture. As plane parallels their errors are in each case less than 1 second of arc. Moreover, as prisms they are mounted in their cells with the refracting edges in a horizontal plane in such manner that at one window the light beam is depressed and at the other window elevated through angles of approximately 0.5 seconds but with entirely negligible lateral deviation. Care was used when mounting the windows to avoid deforming them by the pressure of their retaining rings. Tests on prism-angle measurement, with and without the housing, show agreements within a few tenths of a second with no systematic effect arising from the use of the housing.

\section{CONSTRUCTIONAL DETAILS}

Some details of construction of the prism housing are evident from the accompanying illustrative figures, which, however, are partly diagrammatic. Figure 1 is a sectional elevation of the complete housing showing how the lower clamp and screw serve to orient the superstructure with respect to the base, and also how the upper clamp and screw rotates the single-walled sleeve around the double inner cylinder. These screws are so designed that in each case the knurled head extends toward the observer's station at the times when a particular screw should be used. This automatically prevents the 
inadvertent orientation of the outer window by a procedure that would vitiate the previous adjustment of the other window.

Figure 2 is a sectional plan at the level of the window centers. This shows how the window cells are attached to and carried by the rotating cylinders and also, in connection with figure 1, how the upper prism slide is controlled from the exterior irrespective of the lateral shifts which may occur because it is mounted on the lower slide. For this purpose the nut $k$, which travels on the screw l, engages at all times with a slot $m$ in the roof of the recessed cavity under the upper slide. The manipulation of these slides from without the housing is especially advantageous because delays in attaining

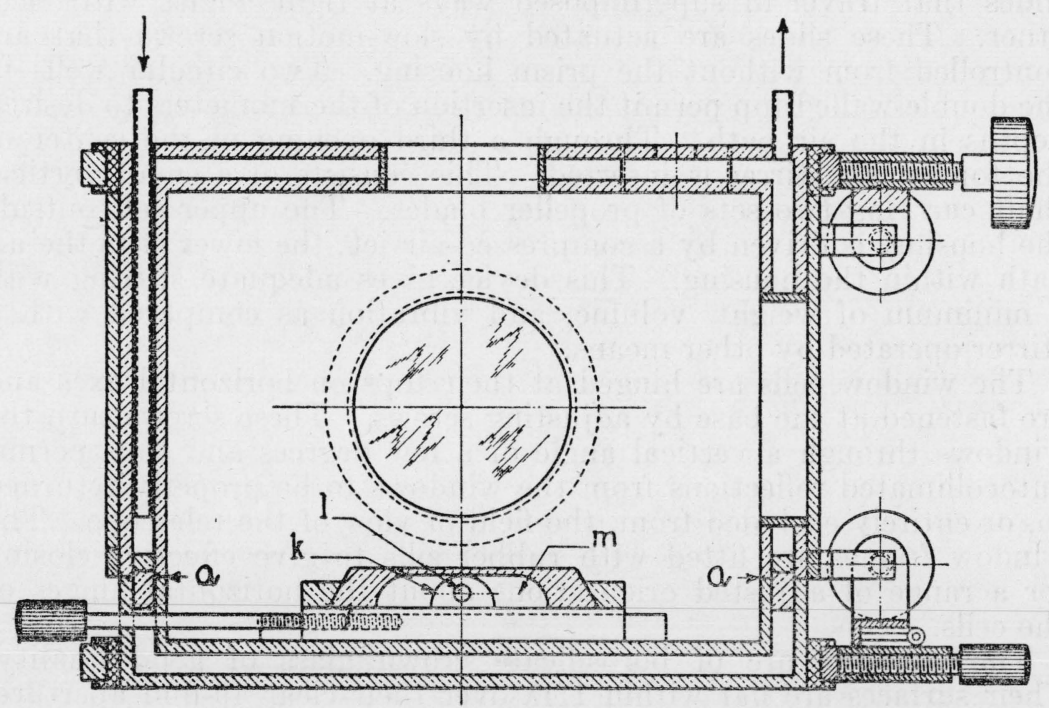

Figure 1.-Sectional elevation of prism housing, showing junction between base and superstructure at aa.

temperature equilibrium would result if, after angle measurement, the housing were opened to translate $^{9}$ the prism to the deviation position.

Figure 3 is a top view of the superstructure. The central well in the top is large in order to accommodate a long-stem mercury thermometer, if such is used, in a hollow prism during its requisite translational adjustment on the slides for either angle or deviation measurement. In such a case the thermometer stem extends through a thick pad of felt which effectually closes the opening and the air stirrer (with its similar pad of felt) is transferred to one of the thermometer wells. These smaller wells at each side of the central well are threaded to receive the protective metal casings in which are housed the mercury thermometers used for determining the air-bath temperatures.

Figure 4 shows how the glass windows are mounted in their cells and secured by retaining rings q. Orientation and adjustment about their horizontal axes or hinges is provided by the friction thumb screws r.

\footnotetext{
${ }^{\circ}$ See p. 31 and 35 of BS J. Research 11 (1933) RP575.
} 
The prism inlet and outlet connections, $\mathrm{s}$ and $\mathrm{t}$, shown in figure 2, provide for inserting the intimate jacketing system of a hollow prism that is used when measuring the refractive indices of liquids. At other times they are short-circuited by a semicircular connection or by a radiating coil of a few turns of copper tubing. Under various working conditions the sequence of flow through the jacketing connections (indicated in only one particular manner on these diagrams) is varied to secure greater uniformity of temperature or a decreased lag in response to the action of the thermoregulator.

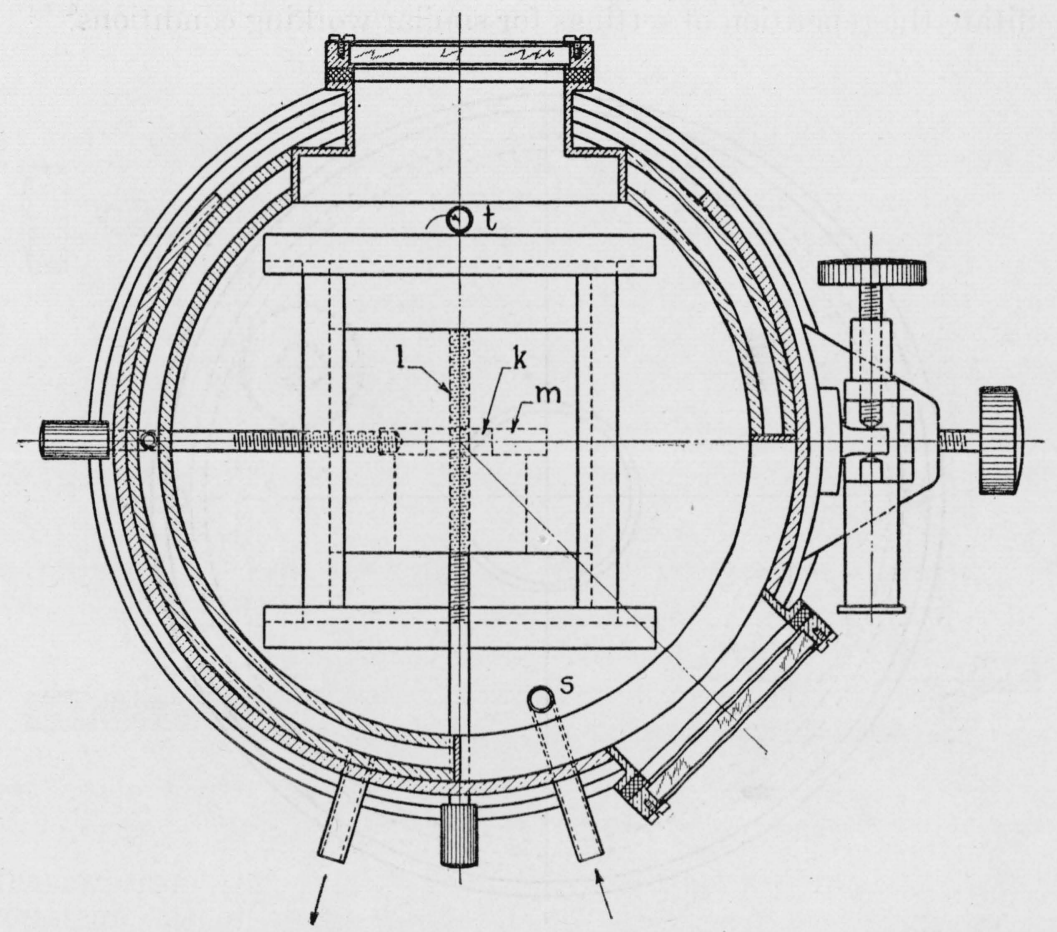

Figure 2.-Sectional plan of prism housing at level of window centers and plan view of prism slides.

\section{JACKETING CIRCUIT}

On a shelf, directly above the spectrometer but suspended from the ceiling, are located a motor, a rotary pump, and a mixing or conditioning chamber which contains a thermoregulator of the usual bulb and U-tube type with toluol as the expansive medium and with a movable platinum wire which makes contact with mercury in a capillary tube to provide for fine adjustment. For settings at widely different temperatures it is necessary, however, to vary the amount of toluol in the bulb by means of a glass plunger which separates the effective bulb from a reservoir. A useful feature, which has been tried with some success for rapid and fairly precise gross adjustments of this kind, is the attachment of a metal bellows to the expansion bulb in order that the volume may be varied by a screw that carries a graduated disk. 
Three fixed rates of heating are provided by leads to resistance coils in the walls of the mixing chamber, and a lamp operated by current through a relay is partially immersed in the tempering bath to constitute the variable heating element. A constant rate of cooling is effected by means of a continuous flow of tap water from a constanthead storage tank through a coil surrounded by melting ice. This cold water traverses a coil immersed directly in the tempering bath of the jacketing fluid within the mixing chamber and thence passes to the sink. Rate of flow in this cooling circuit is regulated by a cock provided with a long pointer that moves over a graduated are to facilitate the repetition of settings for similar working conditions.

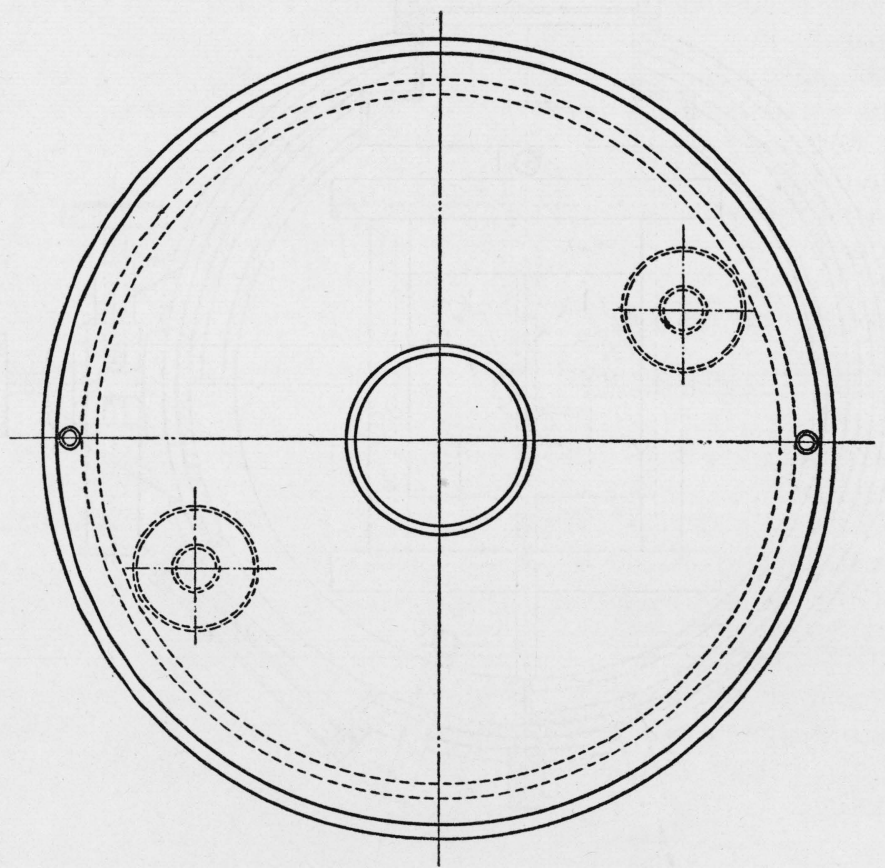

FIGURE 3.-Top view of superstructure of prism housing, showing wells for air stirrer and thermometers, also inlet and outlet of water jacket.

Through a series of copper pipes and rubber hose connections the jacketing fluid follows a closed circuit, as diagrammed in figure 5, which includes pump, mixing chamber, the prism-housing base, and the superstructure of the housing. The system is designed to operate between the approximate limits 0 and $60^{\circ} \mathrm{C}$. For temperatures at and near $0^{\circ} \mathrm{C}$ it is, of course, necessary to use some antifreeze solution in the jacketing circuit and to replace tap-water cooling by a more direct arrangement with a portion of the jacketing fluid flowing through a by-pass which includes a coil immersed in a freezing mixture.

\section{SUSPENSION AND COUNTERBALANCE}

To avoid undesirable weight on the prism table and on the spectrometer a piano-wire suspension with counterweight was devised with a pulley at the ceiling directly over the spectrometer axis. A 
three-point wire suspension, with turnbuckles in two of the wires, was attached to the superstructure of the housing, and to further lessen torque a chain of three circular steel rings was used just above the triple junction which is approximately 18 inches above the housing top. The counterweight consists of a lead-filled brass tube perforated longitudinally to slide freely for a distance of about 15 inches on a vertical guide rod which is securely attached to the ceiling. The weights of all hose connections to the prism housing are likewise carried by this device. A horizontally sliding shelf about 13 inches above the prism table (but entirely independent of the spectrometer and its supporting table) receives the prism housing when it is elevated for the installation or removal of a prism.

Experience in the use of this housing, and tests of the adjustments of the spectrometer which are made at various times, indicate that the residual weight which rests on the prism table of the instrument does not cause any appreciable errors in angle
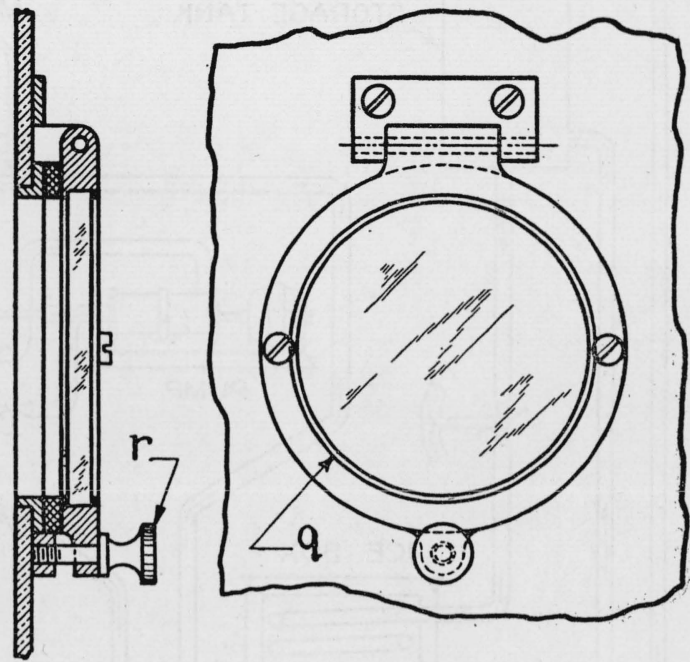

FigURe 4.-Details of window cells and adjustable mounting.

measurements. Moreover, careful tests have failed to show that appreciable torque is introduced even when the arbitrary orientations in azimuth materially exceed those occurring during regular use of the housing.

\section{OPERATIONAL PROCEDURE}

In determining an index of refraction, using this prism housing, the additional operations (as compared with procedure otherwise followed) are briefly named as (1) the adjustment of the thermoregulator and its system, and (2) the proper orientations of the windows of the housing. The time required is essentially that which is necessary in establishing a constant thermal condition in the apparatus, and most manipulations of the prism and its housing are easily made while waiting for equilibrium conditions.

\section{REFRACTING-ANGLE MEASUREMENTS (BY AUTOCOLLIMATION)}

It is advisable to make refracting-angle measurements before deviation measurements because the thermal requirements are probably somewhat less exacting. Immediately after starting the regulatory system, the prism is mounted ${ }^{10}$ on a suitable glass slab on the upper

\footnotetext{
10 Wax in very small quantities is very satisfactory for general use in attaching prisms to the brass slide or to an intermediate block of glass or of asbestos plate. Soft pitch has also been used at temperatures above $40^{\circ} \mathrm{C}$. An auxiliary prism holder, provided with leveling screws and a platform adjustable in height, would be a great convenience, and, moreover, it would obviate a slight tilting of the whole housing that otherwise occurs in the process of leveling.
} 
prism slide and the prism table is approximately leveled. Next, the housing is lowered and the windows oriented by hand to approximately the angle between the prism faces, using for these orientations certain fiducial marks or scales on the side of the housing. By means of the prism-slide controls the prism is then properly "centered" 11 for angle measurement while the observer views the exit pupil of the

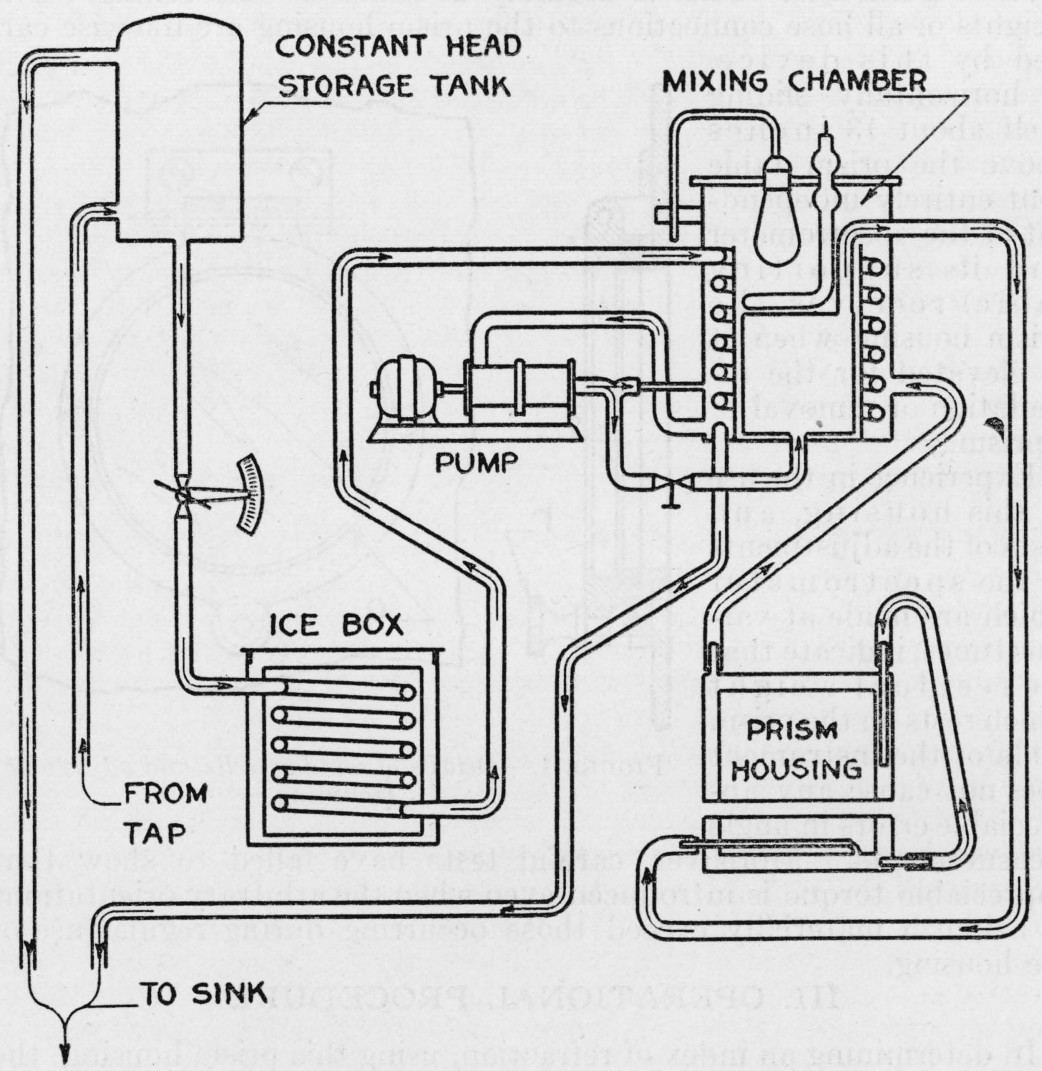

FIgURE 5.-Diagram of water-jacketing circuit and temperature control system.

This figure is not drawn to scale. The hose connections from mixing chamber to prism housing are long and flexible and their weight, like that of the housing, is largely supported by a counterweight and wire over a pulley attached to the ceiling.

autocollimator with an auxiliary eyepiece or magnifier. After this, using autocollimation, the "fixed window" of the inner cylinder is adjusted (with the lower clamp and screw) until it is parallel to one of the prism faces and then (by the upper clamp and screw) the "movable window" of the sleeve is brought parallel to the second face of the prism. Usually the windows must be adjusted slightly about their horizontal (hinge) axes to permit them to act as useful reflectors and, finally, they are slightly depressed so reflections therefrom do not interfere with the refracting-angle measurements, which are made only after an accurate leveling of the prism.

11 See p. 31 of third citation in footnote 1, p. 389. 


\section{MINIMUM-DEVIATION MEASUREMENTS}

After refracting-angle measurements both clamps are loosened and the windows set by hand to the approximate angle which (from experience) is estimated as suitable for double-deviation measurements. The superstructure of the housing is oriented by hand about 180 degrees on its base and the whole prism table, prism, and housing is so oriented that the prism is approximately in the position for minimum deviation to the observer's left. ${ }^{12}$ Then the superstructure is so oriented on its base that the fixed window is approximately normal to the emergent rays. With the aid of autocollimated reflections and using the slide controls the apex of the prism should next be moved toward the spectrometer axis until the prism is uniquely ${ }^{13}$ placed for deviations, and after that a normal setting of the fixed window is accurately obtained by the lower clamp and screw.

Both prism table and telescope are then turned to their respective positions for right-hand deviation and the upper clamp and screw are used for securing a normal setting of the movable window with respect to the emergent light. On account of the symmetry of the minimumdeviation position the fixed window is now normal to the incident rays from the collimator and, also, when the orientations are again changed for left-hand deviation, the movable window will necessarily be normal to the collimated beam.

The maintenance of the prism level during the prism translations and the housing orientations can be checked by a glance at the (deviated) image of the slit which for this purpose should have a horizontal fiducial wire or mark. As a check on several important adjustments, the (magnified) exit pupil of the telescope should be examined from the right- as well as from the left-hand deviation position. Both examinations should show coincidence, at the prism image center, of images of vertical wires ${ }^{14}$ that should be mounted at each of the objectives.

Concerning the above mentioned details of operation it should be remembered that some, such as the proper translations of the prism, must be executed irrespective of the use of a prism housing. Others, such as the normal settings of the windows, do not require really precise adjustments. Refraction at an interface between air at different temperatures is the only error to be eliminated. Assuming the unfavorable condition with error of like sign at each window, it is found that an angular tolerance for one window, corresponding to $\pm 1 \times 10^{-6}$ as the permissible error in refractive index, may be written as

$$
T_{\mathrm{w}}=\frac{T_{2 D}}{4 \Delta \mu},
$$

\footnotetext{
${ }_{12}$ An observer standing somewhat to the left of the instrument and viewing through the prism a deviated image of the collimator slit can, by hand and unaided eye, approximately orient the prism for minimum deviation. Almost at the same time he can, in any well-lighted room, adjust the fixed window so that it is approximately normal to an emergent ray by simply viewing the image of his eye as reflected by the glass of that window.

${ }_{13}$ See p. 31 and 35 of third citation in footnote 1 , p. 389 . If the prism is symmetrically placed on the upper slide, and if it has been properly centered for angle measurement, then only the upper slide need be used in translating the prism from the angle position to that for deviation. Should examinations of the exit pupil of the telescope shown on coincidence of images of the vertically centered threads at the objectives, then such coincidence must be secured by using the screw that controls lateral or transverse translation of the prism.

14 See footnote 13, also the writer's remarks on proper tabling of prisms, BS J. Research 11, 39 (1933) RP575.
} 
where $T_{2 D}$ is a tolerance in (double) minimum-deviation measurement that has already been evaluated ${ }^{15}$ and $\Delta \mu$ for air cannot exceed 0.00004 for use of the housing in the laboratory at controlled housing temperatures in the range 0 to $60^{\circ} \mathrm{C}$. For prisms with refracting angles of 30 degrees the tolerance in normality of each window adjustment is found to be about 0.4 degree while for 60 -degree prisms the tolerance is from $2 \frac{1}{2}$ to 5 times as large. If the housing windows are oriented for deviation while observing for some wave length near the midrange of the frequencies that are to be used, then for work over the whole visible spectrum it is unnecessary to readjust the windows except possibly when working with media of fairly high dispersive properties at extremes of the above-mentioned temperature range.

Thus, it seems appropriate to emphasize that, in general, the operations incident to the use of this prism housing, and also most other adjustments of the prism, can be performed while waiting for satisfactorily constant thermal conditions for refractive-index measurements. To give an idea of the rate of working possible in determining index of refraction as outlined here it may be added that in a certain instance 48 determinations of refracting angle and 52 determinations of minimum deviation on a total of 12 prisms were made (by a single observer) in 42 working hours. Each of these 100 determinations consisted of angle measurements for each of three positions of the circular scale of the spectrometer, together with adequate thermometer, barometer, and hygrometric readings, all of which were taken by the same observer for use in making reductions to standard conditions.

\section{TYPICAL TEMPERATURE COEFFICIENTS OF REFRACTION AND DISPERSION}

The above-described housing has been in general use for several years for precise refractive-index measurements at definite temperatures ${ }^{16}$ usually not far removed from those of the room. In order to further test the housing it was used to determine the refractive index and dispersion of a 60 -degree prism of "medium flint" optical glass ${ }^{17}$ at the temperatures $5,15,25,35$, and $45^{\circ} \mathrm{C}$. Five wave lengths were used and minimum deviations were in most cases determined six times, using various portions of the spectrometer circle. The prism angle was determined for three circle positions at $15^{\circ} \mathrm{C}$ and again, in like manner, at $35^{\circ} \mathrm{C}$. Temperatures and humidities were determined for the air inside the housing and the barometer was read during all observations. All indices are corrected to refer to dry air at the same temperature as that of the glass and at a pressure of $760 \mathrm{~mm}$ of mercury.

\footnotetext{
15 See formula 9 and figure 2 on p. 921 and 922 of first citation in footnote 1, p. 389 .

16 See, for example, p. 721 of BS Sci. Pap. 22 (1928), or p. 624 of BS J. Research 3 (1929).

17 National Bureau of Standards melt 494. The density of the prism is 3.3491 at $25^{\circ} \mathrm{C}$. An analysis gave the following composition:

$\begin{array}{lllll}\mathrm{SiO}_{2} \ldots & \mathrm{Na}_{2} \mathrm{O} \ldots \ldots & 2.69 & \mathrm{Al}_{2} \mathrm{O}_{3} \ldots \ldots & \ldots .65 \\ \mathrm{PbO} \ldots \ldots & \mathrm{K}_{2} \mathrm{O} \ldots \ldots .14 & \mathrm{Fe}_{2} \mathrm{O}_{3} \ldots \ldots & \ldots .02\end{array}$

CaO ...... Tràce.

MgO..... Not detected.
}

See also, A. Q. Tool and E. E. Hill, J. Soc. Glass Tech. 9, 196 (1925). 
TABLE 1.-Room-temperature variations in optical density of a medium fint optical glass (smoothed values from observed data by the process of graduation)

$\left(n_{\mathrm{O}}-n_{\mathrm{S}} \equiv\right.$ observed minus smoothed indices $\left.\times 10^{7}\right)$

$\left[\Delta n \equiv\left(n_{t 2}-n_{t 1}\right) \times 10^{7}\right]$

\begin{tabular}{|c|c|c|c|c|c|c|c|c|c|c|c|c|c|c|c|c|c|c|c|}
\hline \multirow{3}{*}{$\begin{array}{l}\text { Tem- } \\
\text { pera- } \\
\text { ture } \\
\left({ }^{\circ} \mathrm{C}\right)\end{array}$} & \multicolumn{16}{|c|}{ Refractive index (referred to dry air at $t^{\circ} \mathrm{C}$ and pressure of $760 \mathrm{~mm}$ of $\mathrm{Hg}$ ) } & \multicolumn{3}{|c|}{ Dispersion } \\
\hline & \multicolumn{3}{|c|}{$\lambda=6562.8 \mathrm{~A}$} & \multicolumn{3}{|c|}{$\lambda=5895.9 \mathrm{~A}$} & \multicolumn{3}{|c|}{$\lambda=4861.3 \mathrm{~A}$} & \multicolumn{3}{|c|}{$\lambda=4358.3 \mathrm{~A}$} & \multicolumn{3}{|c|}{$\lambda=4046.6 \mathrm{~A}$} & \multirow{2}{*}{$\begin{array}{c}\text { Aver- } \\
\text { age } \\
n_{\mathrm{O}}-n_{\mathrm{S}}\end{array}$} & \multirow{2}{*}{$\begin{array}{c}\frac{n_{D}-1}{\nu=} \\
n_{F}-n_{C}\end{array}$} & \multirow{2}{*}{$\nu 0-\nu \mathrm{s}$} & \multirow{2}{*}{$\begin{array}{l}\Delta \nu \text { for } \\
1^{\circ} \mathrm{C}\end{array}$} \\
\hline & $n_{C}$ & $n_{0}-n_{\mathbf{S}}$ & $\begin{array}{c}\Delta n \text { for } \\
1^{\circ} \mathrm{C}\end{array}$ & $n_{D 1}$ & $n_{\mathrm{O}}-n_{\mathrm{S}}$ & $\begin{array}{c}\Delta n \text { for } \\
1^{\circ} \mathrm{C}\end{array}$ & $n_{P}$ & $n_{0}-n_{\mathrm{S}}$ & $\begin{array}{l}\Delta n \text { for } \\
1^{\circ} \mathrm{C}\end{array}$ & $n_{0}$ & $n_{\mathrm{O}}-n_{\mathrm{S}}$ & $\begin{array}{l}\Delta n \text { for } \\
1^{\circ} \mathrm{C}\end{array}$ & $n_{h}$ & $n_{0}-n_{\mathrm{S}}$ & $\begin{array}{c}\Delta n \text { for } \\
1^{\circ} \mathrm{C}\end{array}$ & & & & \\
\hline $\begin{array}{l}45 .-- \\
40 \ldots\end{array}$ & 1.5858270 & & 41.6 & 1.5901003 & -1 & 45.1 & 1. 6008151 & -1 & 54. & 1.6094637 & -1 & 63.5 & 1.6169217 & -13 & 72.9 & -3 & \begin{tabular}{|c|c|c|}
39.3713 \\
\end{tabular} & +0.0002 & -0.00309 \\
\hline & 1.5857854 & +10 & & 1.5900552 & +9 & & 1.6007606 & +1 & & 1.6094002 & +1 & & 1. 6168488 & +13 & & +7 & 39.4022 & +0.0024 & \\
\hline 25 & 1.5857455 & -3 & 39.9 & 1.5900118 & $-\overline{7}$ & & 1.6007078 & +2 & & 1.6093384 & -4 & 61.8 & 1. 6167776 & -13 & 11.2 & -5 & 39.4332 & -0.0013 & -0.00310 \\
\hline 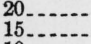 & 1.5857073 & +5 & $\begin{array}{l}38.2 \\
-\cdot .\end{array}$ & 1. $\overline{5899701}$ & -4 & 41.7 & 1.600656 & -3 & 51.1 & \begin{tabular}{|l|}
1.6092783 \\
1.6
\end{tabular} & +5 & 60.1 & 1.6167081 & +24 & 69.5 & +5 & $\mid \begin{array}{l} \\
99.4645 \\
\end{array}$ & $\overline{+0.0021}$ & -0.00313 \\
\hline $10 \ldots$ & & -2 & 36.5 & 1. 5899301 & -1 & 40.0 & & & 49.4 & 1.6092199 & & 58.4 & 1.6166403 & -12 & 67.8 & -4 & $-39,4959$ & -0.0006 & -0.00314 \\
\hline & $1.5856 \% 08$ & & & & & & & & & & & & 1.0100405 & & & -4 & 39. 4959 & -0.0000 & \\
\hline
\end{tabular}

NotE.-The average observational imprecision evidenced by these data is $6 \times 10^{-7}$ in measured refractive index. 
These data were adjusted by the process of graduation or smoothing, using double differences and assuming that $\Delta^{2} n$ for $1^{\circ} \mathrm{C}$ has a constant value (which is found to be $1.7 \times 10^{-8}$ ), and all results are given in table 1 . The average net residuals (observed minus smoothed indices), as tabulated in column 17 for the various temperatures, evidence a freedom from systematic error in temperatures. From this result and from similar evidence in the temperature range 15 to $55^{\circ} \mathrm{C}$ it is concluded that this constant-temperature prism housing is satisfactory in the range for which it was designed, namely, from 0 to $60^{\circ} \mathrm{C}$.

Washington, July 21, 1936. 